\title{
Multinodüler Guatrlı Bir Olguda Tiroid Hemiagenezi
}

\author{
Thyroid Hemiagenesis in a Case of Multinodular Goiter
}

Ahmet KOCAEL ${ }^{1}$, Anıl ORHAN ${ }^{1}$, Betül VATANKULU² ${ }^{2}$,ülçin ERCAN ${ }^{3}$, Zekeriya KARADUMAN ${ }^{1}$, Pinar KOCAEL ${ }^{1}$, Kenan ULUALP ${ }^{1}$

${ }^{1}$ İstanbul Üniversitesi, Cerrahpaşa Tip Fakültesi, Genel Cerrahi AD, ISTANBUL

${ }^{2}$ Ístanbul Üniversitesi, Cerrahpaşa Tıp Fakültesi, Nükleer Tıp AD, ISTANBUL

${ }^{3}$ Bağcılar Ĕ̆itim Araştırma Hastanesi, Genel Cerrahi Kliniği, İSTANBUL

\begin{abstract}
ÖZET
Tiroid hastalıkları Dünya popülasyonu üzerinde her geçen gün daha sık görülür hale gelmektedir. Her ne kadar klinisyenler tiroid bezinin oto-immün ve malign problemlerine odaklansa da anatomik ve embriyolojik patolojiler de göz önünde bulundurulmalıdır. Tiroid bezinin gelişimsel anomalileri nadirdir ve hemiagenezi yaklaşık \%0,05-0,2 sıklıkta ve genellikle sol lobun yokluğuyla görülür. 38 yaşında bayan hasta kliniğimize uzun süredir devam eden, boyunda şişlik ve ağrı şikâyeti ile başvurdu. Muayene ile tiroidin sağ lobunda belirgin büyüme mevcuttu. Tiroid fonksiyon testleri normal olan hastanın radyolojik ve sintigrafik incelemelerinde tiroid bezi sağ lobunda en büyügü $20 \mathrm{~mm}$ olan multiple hipoekoik nodüller tespit edilirken, sol lobu ise tespit edilemedi. İnce iğne aspirasyon biyopsi ile yapılan sitolojik değerlendirme sonucunun kuşkulu olarak bildirilmesi üzerine, hastaya sağ total lobektomi uyguland. Ameliyat esnasında yapılan değerlendirmede sol lob izlenmedi. Postoperatif histopatolojik değerlendirmesinde sağ lobun tamamında multiple kolloidal benign nodüller saptand1.

Cerrahi girişim planlanan vakalarda diğer lobun durumunu bilmek, yapılacak olan tek taraflı lobektomiler sonrası tiroid bezinin total kaybına neden olmak ve hemiagenezi olan tarafa yapılabilecek gereksiz cerrahi girişimleri ve bu nedenle doğabilecek komplikasyonları önleme açısından önemlidir.
\end{abstract}

Anahtar Kelimeler: Hemiagenezi, tiroid, multinoduler guatr

\begin{abstract}
Thyroid diseases are becoming more common in the World. Even though clinicians are focusing on malignant and autoimmune disorders of the gland, anatomical and embryological pathologies must be kept in mind. Developmental disorders of thyroid gland are rare and hemiagenesis of the thyroid gland is detected between 0.05 $0,2 \%$, generally with the absence of left lobe.

A 38 years old female patient attended to our clinic with long term neck pain and swelling. Physical examination revealed an enlargement of right lobe. Thyroid function tests were normal. Radiological test showed multiple hypoechoic nodules in the right lobe which the biggest was $20 \mathrm{~mm}$, and wasn't able to detect the left lobe. Fine needle aspiration was performed and cytological evaluation of the aspiration resulted "suspicious" then right total lobectomy performed to patient due to pre-operative pathology results. Per-operative exploration revealed that there wasn't a left lobe. Postoperative hystopathological examination showed that benign multiple colloidal nodules were at the right total lobe.
\end{abstract}

Evaluation of the opposite lobe is helpful to prevent unnecessary operations and the total loss of the gland for the patients planned undergoing surgical intervention. It's also beneficial to prevent unnecessary explorations and complications at the side which hemiagenesis is detected.

Keywords: Hemiagenesis, thyroid, multinodular goiter 


\section{GíRiş}

Tiroid bezi gestasyonun üçüncü haftasında dil kökünde Foramen Cecum'da ortaya çıkar. Faringeal taslaktaki endodermal hücreler, medial tiroid katlantısını oluşturur ve boyun ön yüzü boyunca normal lokalizasyonuna doğru inmeye başlar. $\mathrm{Bu}$ ilerleyiş esnasında Foramen Cecum ile arasında "Tiroglossal Kanal" adı verilen ve epitel ile döşeli bir kanal meydana gelir. Gestasyonun beşinci haftasında, dördüncü brankial poş’tan meydana gelen lateral katlantılar ile medial katlantı birleşir. Sekizinci ile on birinci haftadan itibaren ise kolloid üretimi başlar (1, 2). Tiroidin konjenital bozuklukları nadir görülen patolojilerdir. En s1k görülen konjenital anomalisi tiroglossal kanal kistidir $(1,3)$. Bunun yanı sıra tiroid bezinin loblarından birinin ya da her ikisinin gelişmemesine bağlı anomalilerde karşımıza çıkabilmektedir. Tiroid glandının parsiyel olarak gelişmemesi "Hemiagenezi", total olarak gelişmemesi ise "Agenezi" olarak isimlendirilir. İlk olarak 1886 yılında Handsfield-Jones tarafından tarif edilmiştir (4).

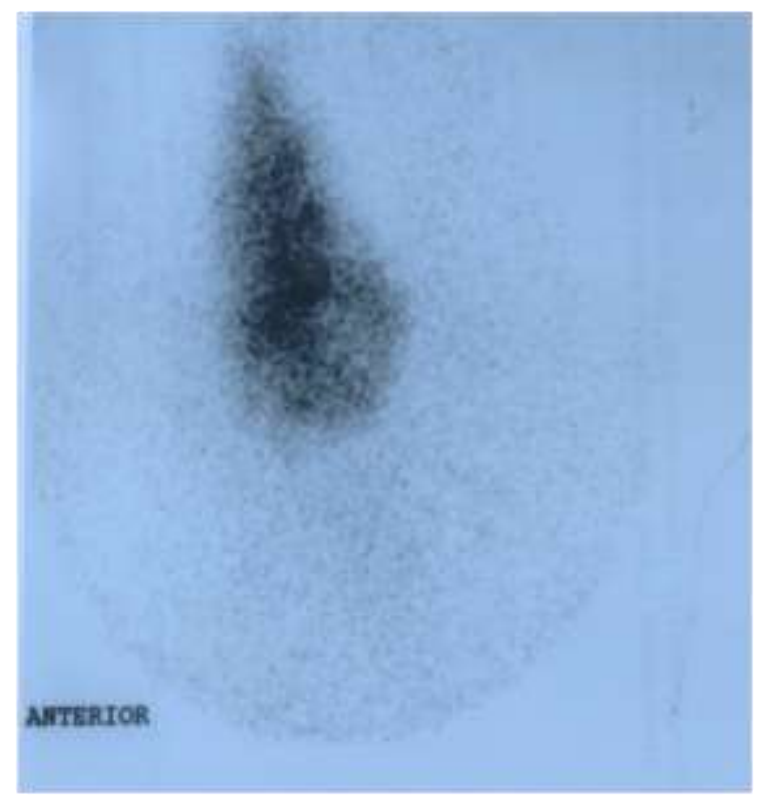

Resim 1: Tiroid Tc 99 Pekteknetat sintigrafisi.
Tiroid hastalıkları Dünya popülasyonu üzerinde her geçen gün daha sık görülür hale gelmektedir. Her ne kadar klinisyenler tiroid bezinin otoimmün ve malign problemlerine odaklansa da anatomik ve embriyolojik patolojilerde göz önünde bulundurulmalıdır. Yazımızda kliniğimize başvuran bir Tiroid Disgenezi vakasını klinik, radyolojik ve patolojik bulguları ile sunmayı ve güncel literatür bilgilerini vermeyi amaçladık.

\section{OLGU}

38 yaşında bayan hasta kliniğimize uzun süredir devam eden, boyunda şişlik ve ağrı şikâyeti ile başvurdu. Hastanın başvurusu esnasında fizik muayenesinde boyun bölgesi sağ tarafında palpe edilebilir şişliği mevcuttu. Hastanın yapılan tiroid ultrasonografi (USG) incelemesinde sağ tiroid lobu boyutları $60 \times 21 \times 24 \mathrm{~mm}$ ve istmus 11x6x5 mm olarak değerlendirildi. Tiroid lobunun konturu hafif lobüle görünümdeydi ve parankim ekoları heterojendi. Tiroid parankimi sağ lobunda $19 \mathrm{~mm}$ çapında içerisinde kistik alanlar izlenen, $21 \mathrm{~mm}, 9 \mathrm{~mm}$ ve $8 \mathrm{~mm}$ çapında nodüller izlendi. Hastanın yapılan Teknesyum (Tc) 99 Pekteknetat sintigrafisinde nodüler hiperplazi mevcuttu. Sağ lobun aktivite dağılımı heterojendi. Sağ lobda yer alan nodül hipoaktifti. Sol lob ise izlenmedi (Resim 1). Hastanın tiroid bezi sağ lobunda bulunan nodüle yönelik olarak İnce iğne aspirasyon biyopsisi yapıldı. Hazırlanan preparatlarda yer yer ezilme artefaktı yapan belirgin görünümde gruplar yapmış tirositler, kolloid ve lenfositler gözlendi. Bunun yanında bir alanda mikrofoliküler patern ve birkaç alanda iri nükleuslu tirositler izlendi. Ameliyata alınan hastada eksplorasyonda sağ tiroid lobunda nodüler büyüme tespit edilirken sol tiroid lobu izlenmedi. Hastaya Sağ Total Lobektomi + İstmektomi işlemi uygulandi. Takipleri esnasında herhangi bir komplikasyon izlenmeyen hasta şifa ile taburcu edildi. Tiroidektomi sonrası gönderilen örnekte, nodüler hiperplazi saptand1. 


\section{TARTIŞMA}

Hastaların bir bölümünün asemptomatik olması nedeniyle Tiroid Hemiagenezinin toplumdaki gerçek insidans1 net olarak bilinmemektedir. Ancak yapılan farklı serilerde, kadavra incelemeleri ve literatür taramalarında $1 / 1900-1 / 2675$ oranında tespit edilmiştir (2, 5, 6). Kadınlarda daha sık izlenmekte olup kadın erkek oranı 3:1 şeklindedir $(5,6,7)$. Sol lobun hemiagenezi ile daha sık karşılaşılır. Yapılan en son çalışmalarda PAX8, TTF1,FOXE1, NKX2-5 lokasyonlarında meydana gelen mutasyonların hemiagenezi gelişiminde etkili olabileceği gündeme gelmiştir (8, 9). Hastalar, asemptomatik ve ötiroidi olmaları dışında, hipotiroidi ve hipertiroidi ilişkili semptomlar ile ya da ağrı, şişlik, yutkunma zorluğu gibi organik şikâyetler ile kliniğe başvurabilirler. Olgumuz iki yıldır devam eden boyun ağrısı ve şişlik ile başvurdu. Yapılan tiroid fonksiyon değerlendirmeleri sonucunda ötiroidi olduğu tespit edildi. Hemiagenezi olgularında, hastaların normal bir tiroid lobu olması nedeniyle tiroid fonksiyonlarında anlamlı değişimler olmayabilir. Ancak yapılan çalışmalarda ve literatür taramalarında, hastaların \%40'a yakın bir bölümünde tiroid fonksiyon testlerinin bozulduğu ve bunun daha ağırlıklı olarak hipertiroidi şeklinde karşımıza çıkabileceği bildirilmiştir $(2,4,10)$. Ayrıca tiroid hemiagenezi konusu ile ilgili bazı çalışmalarda hasta gruplarının neredeyse tamamının ötiroidi ya da hipertiroidi olduğu görülmüştür. Ancak bu durumun hastalarda tespit edilen tiroid patolojilerine ve çalışmanın yapıldığı bölgenin iyot düzeylerine bağlı olabileceği kanısına varılmıştır (10). Hemiagenezi olgularında diğer tiroid patolojileri de karşımıza çıkabilmektedir. Multinodüler guatr, Hashimoto tiroiditi, Graves hastalığg, toksik soliter nodül ve tiroid maligniteleri bu hasta gruplarında klinisyenlerin karşılaşabileceği patolojiler olarak dikkati çekmektedir (10-17). Farklı patolojilerin varlığı sebebiyle medikal ve cerrahi tedavilerde farklı yaklaşımların uygulaması gereklidir. Ayrıca, hemiagenezinin anatomik ve embriyolojik kökenli bir rahatsızlık olması, bu hasta gruplarında "Ektopik Tiroid Dokusu" varlığının ortaya çıkmasına sebep olabilir ve bu durum daha dikkatli bir şekilde araştırılma zorunluluğunu ortaya çıkarır (3). Mevcut olan ektopik dokunun yeterince araştırılmaması, özellikle malignite tespit edilmiş olgularda ileri dönemde nüks gelişimine sebep olur. Hastaların değerlendirilmesinde tiroid fonksiyon testlerine ve otoimmün panele mutlaka bakılmalıdır. Olgumuzda tiroid fonksiyon testleri ve otoimmün belirteçler normal olarak tespit edilmiştir. Biyokimyasal tetkiklere ek olarak mutlaka radyolojik tetkikler yapılmalı ve lüzum halinde patolojik tetkikler istenmelidir. Ultrasonografi, ucuz, non-invaziv, yaygın uygulanabilir olması sebebiyle tiroid bezinde oluşabilecek patolojileri tespit edebilmesinde oldukça efektif bir tanı yöntemi olup; günümüzde klinisyenlerin ilk tercihi haline gelmiştir. İnsidental olgularda, asemptomatik olan hastaların bir bölümünde tanı USG ile konulmaktadır. Ayrıca, diğer lobda mevcut olan patolojileri ortaya koyması açısından oldukça yardımcıdır (11). Olgumuzun USG incelemesinde sağ tiroid lobu boyutlar1 $60 \times 21 \times 24 \mathrm{~mm}$ ve istmus $11 \times 6 \times 5$ $\mathrm{mm}$ olarak değerlendirildi. Tiroid dokusu hafif lobüle görünümde ve parankim ekosu heterojendi. Tiroid Sintigrafisi görüntülemede ikinci seçenektir. Sintigrafi ile gland ve glandda mevcut olan diğer oluşumların aktivitesi değerlendirilebilir ve tanıyı destekleyebilecek ek veriler elde edilebilir. Tiroid hemiagenezi vakalarında sintigrafide izlenen ve Melcnik ve ark. tarafindan tariflenen "Hokey Sopası" görünümü, bu olgular için tanı koydurucudur (18). Olgumuzda Tc 99 Pekteknetat sintigrafisinde nodüler hiperplazi saptanmıştır. Tiroid hemiagenezi olgularında cerrahi yaklaşım mevcut olan lobun durumu ile kararlaştırılmalıdır ve gereklilik halinde histopatolojik olarak değerlendirilmelidir. $\mathrm{Bu}$ hasta grubunda anatomik varyasyonların olabileceği unutulmamalı, paratiroid gland $1(5,9,18-20)$ ve cerrahi işlem sonrası tedavi göz önünde bulundurulmalıdır (3). Hastada var 
olan glandda patoloji saptanmaması durumunda takip seçeneği akla gelmelidir. Fakat mevcut glandda malignite tespit edilmesi ya da malignite şüphesi olması durumunda tiroidektomi düşünülmelidir. Olgumuzda pre-operatif dönemde alınan biyopsisinde mikrofoliküler patern ve birkaç alanda iri nükleuslu tirositler izlenmesi nedeniyle sağ total lobektomi + istmektomi işlemi uygulanmıştır. Hastamızın bir yıllık takibinde herhangi komplikasyon izlenmemiştir.

Sonuç olarak hemiagenezi, tiroid bezinde konjenital olarak görülebilen sık karşılaşılmayan; ancak klinisyenler tarafindan unutulmaması gereken patolojilerden biridir. $\mathrm{Bu}$ hasta grubunda iyi bir değerlendirme ve tedavi planlaması ciddi avantajlar sağlayacaktır.

\section{KAYNAKLAR}

1. Brunicandi FC, Billiar TR, Dunn DL, Hunter JG, Matthews JB, Pollock RE. Schwartz's Principles of Surgery. $10^{\text {th }}$ ed. McGraw-Hill Inc, 2014: 1688-90.

2. Bhartiya S, Verma A, Basu S, Shukla V. Congenital thyroid hemiagenesis with multinodular goiter. Acta Radiologica Short Reports. 2014; 3: 2047981614530286.

3. Ranade A, Rai R, Pai M, Nayak S, Krisnamurthy A, Narayana S. Anatomical variations of the thyroid gland: possible surgical implications. Singapore Medical Journal. 2008; 49(10): 831-4.

4. Velayutham K, Mahadevan S, Velayutham L, Jayapaul M, Appakalai B, Kannan A. A case of hemiagenesis of thyroid with double ectopic thyroid tissue. Indian Journal of Endocrinology and Metabolism. 2013; 17(4): 756-8.

5. Kroeker TR, Stancoven KM, Preskitt JT. Parathyroid adenoma on the ipsilateral side of thyroid hemiagenesis. Proceedings (Baylor University Medical Center). 2011; 24(2): 92-3.
6. Wu Y-HE, Wein RO, Carter B. Thyroid hemiagenesis: a case series and review of the literature. American Journal of Otolaryngology. 2012; 33: 299-302.

7. Chang J, Gerscovich EO, Dublin AB, McGahan JP. Thyroid hemiagenesis: a rare finding. Journal of Ultrasound in Medicine. 2011; 30: 1309-10.

8. Szczepanek-Parulska E, Szaflarski W, Piątek K, Budny B, Jaszczyńska-Nowinka K, Biczysko M. Alternative 3'acceptor site in the exon 2 of human PAX8 gene resulting in the expression of unknown mRNA variant found in thyroid hemiagenesis and some types of cancers. Acta Biochimica Polonica. 2013; 60: 573-8.

9. Oruci M, Ito Y, Buta M, Radisavljevic Z, Pupic G, Djurisic I, et al. Right thyroid hemiagenesis with adenoma and hyperplasia of parathyroid glandscase report. BMC Endocrine Disorders. 2012; 12: 29 doi: 10.1186/1472-6823-12-29.

10. Ruchala M, Szczepanek E, Szaflarski W, Moczko J, Czarnywojtek A, Pietz L. Increased risk of thyroid pathology in patients with thyroid hemiagenesis: results of a large cohort case-control study. European Journal of Endocrinology. 2010; 162: 153-60.

11. Berker D, Ozuguz U, Isik S, Aydin Y, Ates Tutuncu Y, Akbaba G. A report of ten patients with thyroid hemiagenesis: ultrasound screening in patients with thyroid disease. Swiss Medical Weekly. 2010; 140(7): 118-21.

12. Nsame D, Chadli A, Hallab L, El Aziz S, El Ghomari H, Farouqi A. Thyroid Hemiagenesis Associated with Hashimoto's Thyroiditis. Case Reports in Endocrinology. 2013; 2013: 414506. doi: $10.1155 / 2013 / 414506$.

13. Wang J, Gao L, Song C. Thyroid hemiagenesis associated with medullary or papillary carcinoma: Report of Cases. Head and Neck. 2014; 36: 106-11. 
14. Yeh LS-T, Wang C-Y. Thyroid Hemiagenesis in a Euthyroid man. Journal of Medical Ultrasound. 2010; 18: 79-80.

15. Cakir M, Gonen S, Dikbas O, Ozturk B. Thyroid hemiagenesis with Graves' disease, Graves' ophthalmopathy and multinodular goiter. Internal Medicine. 2009; 48: 1047-9.

16. Vayisoglu Y, Ozcan C, Gen R, Eti CM, Sut H, Gorur K. Thyroid isthmus agenesis associated with thyroid papillary carcinoroid isthmus agenesis associated with thyroid papillary carcinoma. Journal of Craniofacial Surgery. 2013; 24: 428-9.

17. Kocael PÇ, Hepgül GE, Öztürk T, Cihan A. Tiroid cerrahisinde Bağcılar Eğitim Araştırma Hastanesi deneyimimiz. Endokrinolojide Diyalog Dergisi. 2010; 7(2): 63-67.

18. Ferrari CC, Lorenz K, Dionigi G, Dralle H. Surgical strategy for primary hyperparathyreoidism with thyroid hemiagenesis. Langenbeck's Archives of Surgery. 2014; 399: 1077-81.

19. Mydlarz W, Zhang K, Micchelli S, Kim M, Tufano R. Ipsilateral double parathyroid adenoma and thyroid hemiagenesis ORL. 2010; 72: 272-4.

20. Isreb S, Alem F, Smith D. Left thyroid hemiagenesis in a patient with primary hyperparathyroidism. BMJ Case Reports. 2010; 2010: bcr0320102864. 